\title{
Loaisis in Edo State, Nigeria
}

\author{
R.M. Mordi MSC, Ph.da, A.N. Onunu MBBS, FWACP
}

\begin{abstract}
A study to determine the prevalence of loaisis was carried out in Edo State, Nigeria for a period of one year beginning from February 1999 to January 2000. A total of thirteen thousand, two hundred samples were examined. Nine samples $(0.07 \%)$ were positive for Loa loa. The parasite had limited distribution in Edo State. It was observed in only six local government areas namely Uhunmwode, Ikpoba Okha, Igueben, Etsako East, Akoko-Edo and Owan East. The pattern of infection in the various age groups showed clearly that maximum exposure occurred from the third to fifth decade of life. All the positive samples were from males. The prevalence of infection was higher during the rainy (wet) season than in the dry season. The inaccessibility of the arthropod vector to humans could be advanced for the low prevalence of the disease in the state. The socio-cultural and economic factors, which predisposed to infection, were discussed as part of control measures.
\end{abstract}

\section{INTRODUCTION}

Loaisis is an infection caused by the filarial worm Loa loa. The clinical manifestations as well as the pathology particularly in the production of subcutaneous swellings, pains and conjunctivitis have been very elaborately described ${ }^{1,2,4}$. Loaisis is common in developing tropical countries where conditions are suitable for the breeding of the arthropod vectors - Chrysops species. These

KEY WoRDS: Loaisis, Prevalence, Loa Loa, Edo State Nigeria.

${ }^{a}$ R.M. MORDI MSC, Ph.d Department of Medical Microbiology University of Benin Teaching Hospital Benin City, Nigeria. 'A.N. OnumMBBS, FWACP Department of Medicine University of Benin Teaching Hospital Benin City, Nigeria.

Correspondence to: Dr. R.M. MORDI Department of Medical Microbiology University of Benin Teaching Hospital P.M.B. 1111 Benin City, Nigeria. E-Mail: raphael_mordi@yahoo.com flies are canopy lovers and there are lots of warm humid canopy forests in Edo State, which provide ideal breeding habitats for the Chrysops species.

Here in Edo State there is need to estimate the prevalence of loaisis. The estimate of the infection is of importance in the surveillance of the disease in the state. Despite the fact that community studies in some parts of the state have been done, the actual pattern of infection among the population through epidemiological studies of the community is not known for the greater part of the state. The paucity of information currently available as regards loaisis in Edo state necessitated this study. There is need to know the pattern of transmission, distribution and prevalence. Hospital reports are the main source of information on loaisis in the state. Hospital reports are, however, on referred patients and cannot be used to determine pattern of transmission, distribution and prevalence. Again the hospital reports, which are available in the epidemiological unit, State Ministry of

( CMS UNIBEN JMBR 2006; 5 (1) : 12-17 
Health, did not differentiate one filarial worm infection from the other but grouped all filarial infections as filariasis. Such report does not give information on the prevalence of any particular microfilaria. Other aspects of the study were to determine the prevalence of the infection among various age groups, and also determine, if there exists, seasonal and geographical pattern of infection.

\section{MATERIALS AND METHODS Study area:}

This covered a period of one year starting from February 1999 to January 2000. The study was done in all the eighteen (18) local government areas of Edo state. The land area is approximately 19794sq. Kilometers and has a provisional population of 2,159848 . The state lies roughly between longitudes $05^{\circ} 04^{\prime} \mathrm{E}$ and $06^{\circ} 43^{\prime} \mathrm{E}$ and latitudes $05^{\circ} 44^{\prime} \mathrm{N}$ and $07^{\circ} 34^{\prime} \mathrm{N}$. The land cuts across several ecological zones ranging from the coastal mangrove swamps in the south to woodland savanna forest in the northern parts of the state 5.

The multiplicity of ethnic groups has the attendant diversity of cultures, customs and habits, some of which contribute to risk of infection, ${ }^{6,7}$. The major ethnic groups include the Bini's, Esan's, and the Afemai's, while the minority groups include the Urhobo's, Ijaw's, Itsekiri's, Igbanke's and the Yoruba's. The occupations vary from fishing along the coastal areas to mixed crop farming in the middle and northern parts of the state. There are petty traders and businessman while there are civil servants in all the areas. The timber industry flourishes in Edo state because of its extensive forest reserve. A few individuals are involved in timber (tree) felling in the forest.

\section{Sampling technique:}

A few days to sample collection visits were made to the various local government areas to explain the objectives of the study. It was necessary to explain to the local community

\footnotetext{
- CMS UNIBEN JMBR 2006; 5 (2) : 12-17
}

the benefits of the study to them. Many similar studies in the past failed because the local community was more concerned about how to make ends meet as regards feeding and other essentials of life and paid no attention to such studies and thus failed to cooperate ${ }^{8,9,10}$.

Random sampling technique was used in selecting the study subjects from the rural communities in each local government area. Seven hundred and eighty (780) samples were collected from each local government area (Sixty-five samples each month). A total of fourteen thousand and forty (14040) samples were thus collected from all the local government areas of the state, of which thirteen thousand two hundred $(13,200)$ were examined for the presence of loa loa microfilaria. Infection rate according to the various age groups was determined. The gap between each age group was ten years and it ranged from one year to above seventy years. Data were formed on monthly basis to cover the period of study.

\section{Microscopic examination:}

A clean grease-free slide was labeled with the name and age of the donor. The thumb was swabbed with spirit and a finger prick was made with a lancet. Two to three drops of blood were collected on the labeled slide. A cover slip was placed on it and examined with the light microscope using x 10 objective and later $x 40$ objective. If positive the organism will be observed by movement. Identification is by staining with Giemsa stain to see the sheath and caudal nuclei. Procedure for staining was as described by Giemsa ${ }^{11}$.

\section{Statistical analysis:}

Results are presented as tables and charts. The Prevalence rates are reported as percentages.

\section{RESULTS}

A total of thirteen thousand, two hundred samples were examined. Nine (9) samples 
14 Joumal of Medicine and Biomedical Research

were positive for Loa loa. The overall prevalence of the parasite in the state was therefore $0.07 \%$.

This table shows that prevalence was relatively higher between the months of
March to september, a period which corresponds with the rainy (wet) season of the year. The parasite was not detected during the months of November to January (Dry season) .

Table 1. Monthly prevalence of infection in Edo State

\begin{tabular}{|c|c|c|c|c|c|c|c|c|c|c|c|c|}
\hline \\
\hline \multicolumn{13}{|c|}{ 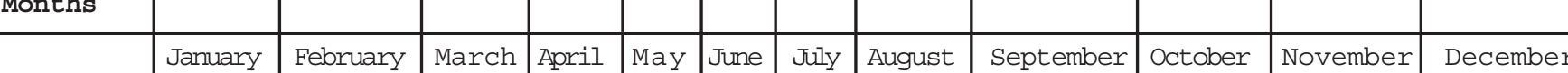 } \\
\hline $\begin{array}{l}\text { Prevalence } \\
(\%)\end{array}$ & 0.00 & 0.04 & 0.07 & 0.09 & 0.04 & 0.06 & 0.12 & 0.11 & 0.18 & 0.13 & 0.00 & 0.00 \\
\hline
\end{tabular}

\section{Monthly Prevalence of Loaisis}

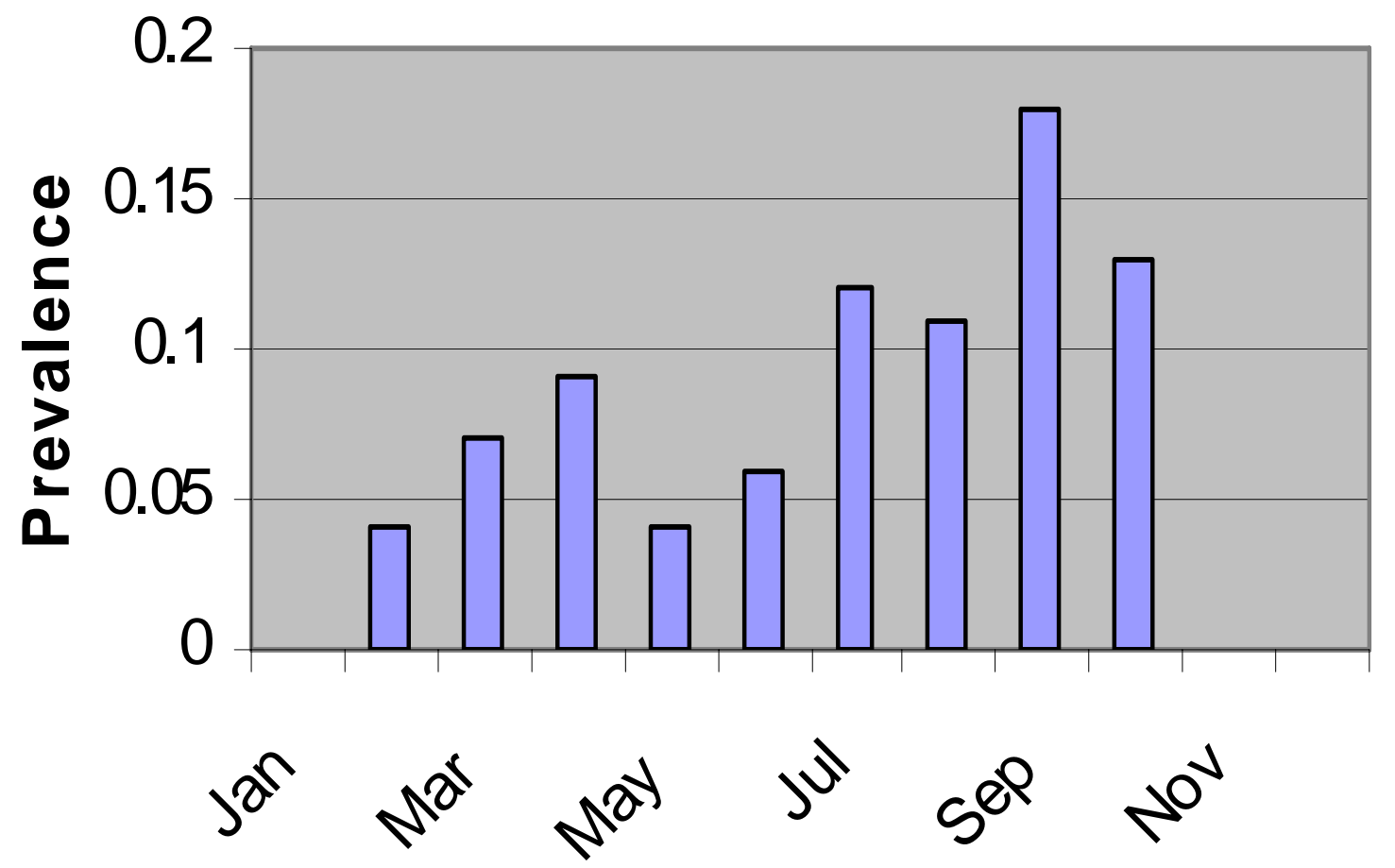

months 
Table 2. Prevalence of infection in the various age groups and gender

\begin{tabular}{llllllllll}
\hline & \multicolumn{3}{c}{ MALES } & \multicolumn{3}{c}{ FEMALES } & \multicolumn{3}{c}{ TOTAL } \\
Age (yrs) & $\mathrm{n}$ & \multicolumn{2}{c}{ positive (\%) } & $\mathrm{n}$ & \multicolumn{2}{c}{ positive (\%) } & $\mathrm{n}$ & \multicolumn{2}{c}{ positive (\%) } \\
\hline $1-10$ & 1000 & 0.0 & $(0.0)$ & 1000 & 0.0 & $(0.0)$ & 2000 & 0.0 & $(0.0)$ \\
$11-20$ & 1000 & 0.0 & $(0.0)$ & 1000 & 0.0 & $(0.0)$ & 2000 & 0.0 & $(0.0)$ \\
$21-30$ & 1000 & 3.0 & $(0.3)$ & 900 & 0.0 & $(0.0)$ & 1900 & 3.0 & $(0.16)$ \\
$31-40$ & 1000 & 4.0 & $(0.4)$ & 800 & 0.0 & $(0.0)$ & 1800 & 4.0 & $(0.22)$ \\
$41-50$ & 1000 & 2.0 & $(0.2)$ & 900 & 0.0 & $(0.0)$ & 1900 & 2.0 & $(0.11)$ \\
$51-60$ & 1000 & 0.0 & $(0.0)$ & 600 & 0.0 & $(0.0)$ & 1600 & 0.0 & $(0.0)$ \\
$61-70$ & 800 & 0.0 & $(0.0)$ & 500 & 0.0 & $(0.0)$ & 1300 & 0.0 & $(0.0)$ \\
$>70$ & 400 & 0.0 & $(0.0)$ & 300 & 0.0 & $(0.0)$ & 700 & 0.0 & $(0.0)$ \\
\hline Total & 7200 & 9.0 & $(0.13)$ & 6000 & 0.0 & $(0.0)$ & 13,200 & 9.0 & $(0.07)$ \\
\hline
\end{tabular}

Result showed that infection was observed only in males in the age groups of between 21 years and 50 years.

\section{Table 3. Prevalence according to local government area}

\begin{tabular}{lccc}
\hline Local government Area & No. of Samples (n) & Positive Samples & Prevalence (\%) \\
\hline Orhionmwon & 780 & 0 & 0.0 \\
Esan North East. & 780 & 0 & 0.0 \\
Esan South West. & 745 & 0 & 0.0 \\
Esan Central & 720 & 0 & 0.0 \\
Esan West & 780 & 0 & 0.0 \\
Igueben & 625 & 1 & 0.16 \\
Oredo & 780 & 2 & 0.26 \\
Uhunmwode & 780 & 1 & 0.13 \\
Ikpoba Okha & 780 & 1 & 0.13 \\
Ovia North East. & 713 & 0 & 0.0 \\
Ovia South & 780 & 0 & 0.0 \\
Egor & 780 & 0 & 0.0 \\
Akoko-Edo & 657 & 0 & 0.0 \\
Etsako East & 780 & 3 & 0.38 \\
Etsako West & 705 & 0 & 0.0 \\
Etsako Central & 695 & 0 & 0.0 \\
Owan East & 610 & 1 & 0.16 \\
Owan West & 710 & 0 & 0.0 \\
\hline
\end{tabular}

\section{DISCUSSION}

The overall prevalence of the parasite in the state was $0.07 \%$. This prevalence value was very low when compared with similar studies elsewhere ${ }^{1,2,3,4,12}$. Reasons that can be advanced for this low prevalence value can be either the sampling technique or the inability of the arthropod vector, Chrysops diminuta to assess humans.

The pattern of infection in the various age groups showed clearly that maximum exposure

(0 CMS UNIBEN JMBR 2006; $5(2): 12-17$ 
occurred at adult age group. This age group, ranging from 21 - 50 years constituted the adult period as shown in table 2. Individuals whose occupations allowed contact between them and Chrysops species fall within this age group. Chrysops diminuta is a canopy lover and so people who have forest - related occupations were most likely to be infected.

The absence of microfilaria in the age groups between 1 year and twenty years was probably because Loa loa takes a long time (about 20 years) to produce a latent microfilaraemia 13.

The infection pattern observed in the various months showed that a relatively higher prevalence between the months of March to september, a period which corresponds with the rainy (wet) season of the year. The parasite was not detected during the months of November to January (Dry season) . The reason advanced for this pattern is the fact that the arthropod vector required warm humid mud and decaying vegetation to lay eggs. Such conditions can only be maintained in the rainy season. The dry season, therefore, did not encourage the breeding of the arthropod vectors.

The pattern of infection in the various local government areas showed that the parasite was not found in all the areas thus showing an uneven geographical distribution. The very low prevalence values and patchy distribution of the parasite in the state stressed the fact that man-fly contact was very low or negligible.

Infections were not observed in the age groups of one year to twenty years. This observation can be explained partly on the reasons of under exposure since these age groups do not have much to do with forest occupations. Again this can be explained partly on the long incubation period of the filarial worm and so the appearance of the microfilaria in peripheral blood may not be observed until after a long time (about 20 years) following infection ${ }^{14,15}$.
Since Chrysops species were the only known vectors of Loaisis the control of the disease can be easily achieved by destroying the breeding habitats. The wearing of clothes is advised for those who are engaged in forestrelated occupations. It is also advised that treatment facilities should be made available in government general hospitals, clinics and health centers for better treatment coverage to the people of Edo State, Nigeria.

Another explanation for the low prevalence value observed in this study may be related to blood collection method. Nathan and Reccurt, 16 claimed that there was a higher concentration of microfilaria in capillary blood from the ear lobe than from finger prick. Unfortunately, it was not possible to obtain blood from the ear lobe due to poor response by the inhabitants. Puncturing the ear lobe is extremely painful and no body was willing to suffer the pain even with the incentive offered.

Measures to control breeding and propagation of Chrysops flies should be instituted in those areas of the state that have been identified in this study as endemic for loaisis. In addition, health education through the mass media for suitable protective clothing, especially for people whose occupations and hobbies bring them in regular contact with forests should be focused in these places. Furthermore, diagnostic and treatment facilities should be made available in the primary health care centers for early diagnosis and treatment before permanent damage occurs.

\section{References}

1 Gerbaux, A., Garin, J.P. and Lenegre, J. Cardiopathy and filariasis. Bull. Soc. Med. Hop. Paris. 1957; 25/26, 873.

2 Bell, D.R. Membrane filters and microfilariae: A new dignostic techque. Ann. Trop. Med. Parasit 1967;61: 220.

3. Ridley, D.S. The complement fixation test in filariasis. Trans. Roy. Soc. Trop. Med. Hyg. 1956; 50: 255.

(๑) CMS UNIBEN JMBR 2006; 5(2): 12-17 
4 Sasa, M. Human filariasis. A global survey of epidemiology and control, Baltimore, University Park, Press. 1976

5. Microsoft Encarta reference library 2002 version.

6. Turshen, M. The political ecology of disease in Tanzania. New Brunswick, NJ. Rutgers University Press. 1984

7. Inhorn, M.C. and Brown, P.J. The anthropology of infections disease. Ann. Rev. Anthropol. 1990;19: 89 - 117.

8. Etkin, N.L. Cultural constructions of efficiency. In S. Vander Guest and S.R. Whyte (eds). The context of medicine in developing countries, Dordrecht. The Netherlands. Klumer Publishers. 1988; pp $299-326$.

9. Rubel, A.J. and Hass, M.R. Ethnomedicine. In: T.M. Johnson and C.F. Sargent (eds) . Medical anthropology: A hand book of theory and method New York Greenwood Press. 1990; pp115 - 131.

10. Good, C.M. Ethnomedical systems in Africa. New York: Guildford Press. 1987.
11. Giemsa, G. Technique for thick blood film Zbl. Bakt. Ref. 1902a; 32,307.

12. Airauhi, L.U., Enosolease, M.E., Wemambu, S.N.C., Ibadin, M.O., Omoigberale, A.I., Halim, N.K.D. Some aspects of the epidemiology of Loaisis in three village communities within the Niger Delta area of Nigeria. Nig. Postgrad. Med. J. 7: (1) March 2000 .

13. Trent Sophie, C. Re-evaluation of world war II veterans with filariasis acquired in the South Pacific. Amer. J. Trop. Med. Hyg. $1963 ; 12: 877$.

14. Ogunba, E.O. Loa loa microfilaria in the Nigerian population. Trop. Geogr/Med. 1977;29: (1) $51-55$.

15. Oguniyi, T.A. Loaisis in Origbo commuity. Ife North Local Government Area of Oyo State Nigeria. Nig. J. Parasit. 1991;12: 39 - 43.

16. Nathan, M.B. and Reccurt, C. Higher concentrations of microfilariae in capillary blood from the ear lobe than from the finger with Wuchereria bancrofti and microfilaria ozzardi infections. Trans. Roy. Soc. Trop. Med. 1979;73 (4) : $455-457$. 